NASA Technical Memorandum 100792

\title{
A Laser Communication Experiment Utilizing the ACT Satellite and an Airborne Laser Transceiver
}

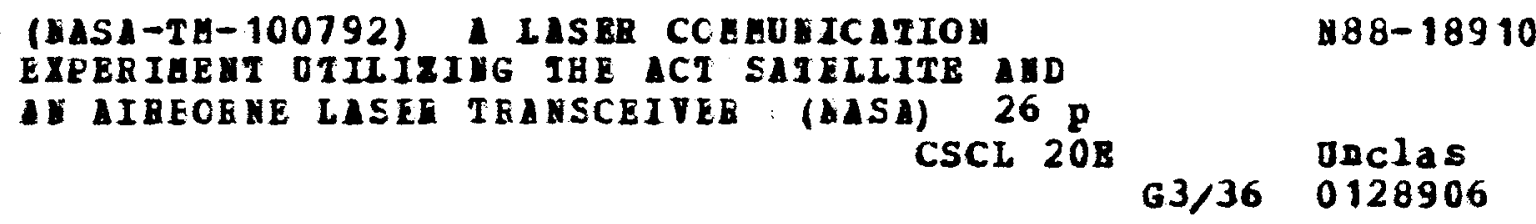

Charles E. Provencher, Jr. and Rodney L. Spence Lewis Research Center

Cleveland, Ohio

Prepared for

Optoelectronics and Laser Applications in Science and Engineering (O-E LASE '88)

sponsored by the Society of Photo-Optical Instrumentation Engineers Los Angeles, California, January 10-17, 1988

\section{Nusn}




\title{
A LASER COMMUNICATION EXPERIMENT UTILIZING THE ACT SATELLITE
}

\author{
AND AN AIRBORNE LASER TRANSCEIVER \\ Charles E. Provencher, Jr. and Rodney L. Spence \\ National Aeronautics and Space Administration \\ Lewis Research Center \\ Cleveland, Ohio 44135
}

\begin{abstract}
The launch of a laser communication transmitter package into geosynchronous earth orbit onboard the Advanced Communications Technology (ACT) satellite will present an excellent opportunity for the experimental reception of laser communication signals transmitted from a space orbit. The ACTS laser package includes both a heterodyne transmitter (Lincoln Labs design) and a direct detection transmitter (Goddard Space Flight Center design) with both sharing some common optical components. NASA Lewis Research Center's Space Electronics Division is planning to perform a space communication experiment utilizing the GSFC direct detection laser transceiver. The laser receiver will be installed within an aircraft provided with a glass port for the reception of the signal. This paper describes the experiment and the approach to performing such an experiment.
\end{abstract}

Described are the constraints placed upon the NASA Lewis experiment by the performance parameters of the laser transmitter and by the ACTS spacecraft operations. The conceptual design of the receiving terminal is given; also included is the anticipated performance capability of the detector.

\section{INTRODUCTION}

In recent years, the interest in using a modulated laser beam as a spaceborne communications transport medium has been growing steadily as evidenced by the number of technical articles published. What has been lacking has been the opportunity for hands-on experience with such systems. The Advanced Communications Technology Satellite, a project of NASA Lewis Research Center with extensive industry participation, is scheduled for launch in the spring of 1991. It is planned to have on-board a laser communication package. Included in the package will be a heterodyne laser transceiver, a project of Lincoln Labs, and a direct detection laser transceiver, a project of NASA Goddard Space Flight Center. Also included will be an acquisition and tracking system, being implemented by Lincoln Labs. The presence of this laser transmitter and receiver in geosynchronous orbit will offer experimenters a rare opportunity for hands on activities with laser communication systems. It is the current intention of NASA Lewis' Space Electronics Division to perform a series of experiments utilizing the direct detection laser package on ACTS. This paper will describe SED's approach to performing the experiment, and a brief description of the calculations involved. 


\section{DESCRIPTION OF ACTS}

A current, major project of NASA Lewis is the Advanced Communications Technology Satellite with a launch planned for the Second Quarter of 1991. Much has already been published about ACTS so very brief comments will suffice here. This satellite has on-board many unique technology items such as a matrix switch, a baseband processor, and a multiple beam antenna that produces steerable beams. Also included is an operating communication frequency of $30 \mathrm{GHz}$ for the uplink and $20 \mathrm{GHZ}$ for the downlink. A part of the ACTS system is a versatile earth terminal, the High Bit Rate-Link Evaluation Terminal (HBR-LET), to provide maximum flexibility of operations for experimenters. The satellite is intended to be utilized intensely as an experimenters test bed during the first years of its life, and the ACTS project office is actively seeking experimenters.

Another feature which adds considerably to ACTS uniqueness is the presence of a laser communication package on-board the satellite. This device will permit ACTS to be used for combined RF/laser communication experiments, a rare opportunity in space.

The laser communication package for the ACTS is the result of a collaboration between MIT's Lincoln Labs, which has performed the development of a heterodyne laser system as well as the acquisition and tracking technology, and Goddard Space Flight Center (GSFC), which has developed the direct detection portion of the package. The hardware for these items is being produced by aerospace hardware fabricating contractors.

Figure 1 is an illustration of the ACTS system showing the RF communication links and the associated terrestrial system.

Both Lincoln Labs and GSFC are currently planning on utilizing satellite to earth laser links for the initial operation of the laser communications package. In selecting a concept for a laser communication experiment by NASA Lewis' Space Electronics Division, it was decided that another satellite-toearth link would not add useful data to that planned for by LL and GSFC. Therefore, consideration was given to a spaceborne or airborne laser terminal. An examination of the costs and difficulties of implementing a spaceborne laser experiment led to the decision to perform the experiments with an airborne laser transceiver. Availability of suitable aircraft such as WPAFB's Laser Communications Test Bed (ref. 1) was a deciding factor. Figure 2 shows the links involved, a duplex laser link between spacecraft and aircraft, and the $30 / 20 \mathrm{GHz}$ RF link between spacecraft and the HBR-LET earth terminal. The $30 / 20 \mathrm{GHZ}$ link can be considered firm as both the satellite and the HBR-LET design and hardware phases are well underway. The lasercom package design and hardware phases are also underway but the severe technical difficulties of this effort are causing a series of adjustments as the program has progressed. Thus, there are uncertainties as to the status and specific parameters of the lasercom final product. Consequently, what is being described in this paper is proposed laser communication experiment, and the link parameters stated here will not necessarily be the final ones. Figure 2 displays what is presently anticipated as the NASA Lewis-SED lasercom experiment at the time when ACTS is launched. 


\section{EXPERIMENT DESCRIPTION}

NASA Lewis is proposing to do a lasercom experiment using the on-board direct detection equipment developed by GSFC with the acquisition and tracking systems developed by Lincoln Labs. The NASA Lewis lasercom package is currently anticipated to be a transceiver, mounted on an actively stabilized platform in a large transport type aircraft. The aircraft fuselage would need to contain a window of suitable material for transmission of the laser beams into and out of the aircraft. The lasercom package will include a microprocesser which will aim the lasercom optics at the ACTS, the electronics needed to store the received communication bit stream and then initiate its transmission back to the satellite. There will also be equipment for measuring the bit error rate of the incoming bit stream. Figure 3 is a block diagram of the transceiver and its associated equipment.

An experiment data point would be obtained by transmitting a random bit stream of specific rate ranging from 1.72 to $220 \mathrm{Mbps}$ and with a zero BER from the RF earth terminal up to the ACTS. On-board the ACTS, the $30 \mathrm{GHz}$ signal is converted to a laser signal and transmitted from ACTS via the direct detection laser transmitter (after acquisition has occurred and tracking initiated) to the airborne receiver. The incoming signal will have its BER measured and then will be returned to ACTS via a direct detection laser channel, and thence to the RF earth terminal as a $20 \mathrm{GHz}$ signal and again the BER will be measured.

There are two possible options for handling the data stream. One, as just described is to have the original data stream complete the entire circuit, $\dot{i} . e$, earth terminal to ACTS, thence to aircraft and return, and then back to earth. This would simulate a communication channel in which the airborne laser transceiver served as a repeater and all incoming errors were retransmitted. However, baseband processing appears to be a future reality, and so for our experiment, baseband processing could be simulated in one sense by not retransmitting errors in the signal arriving at the aircraft, but instead originating a new data stream of zero BER and transmitting this signal to ACTS and then to the earth terminal. Studies have not yet been performed to determine which option should be utilized for the NASA Lewis lasercom experiment. For this paper, it is assumed that the first option will be utilized and that the incoming signal to the airborne transceiver will be retransmitted including its errors. This situation could change, because prior to final design of the experiment, a Phase A type study sponsored by NASA Lewis will be performed to provide an accurate and more complete definition of the experiment.

Although BER measurements would be the prime test result, and is the test parameter that could be the primary determinant in selecting the length of test runs, many other factors would be measured. Parameters concerned with the aircraft velocity and attitude relating to the spacecraft need to be measured, plus information describing the performance of the isolation optical bench upon which the transceiver is mounted. This information will be required in order to achieve acquisition and tracking and to assess how well these systems performed during the test.

In order to verify the link calculations, various losses will need to be measured. This will involve collecting data on atmospheric conditions, both at the aircraft itse if and from wide area NOAA observations. Specific details on type and quantity of this data are yet to be determined. Some losses such 
as optical losses are intrinsic to the hardware and must be obtained by test measurement after the hardware has been fabricated. However, some items such as laser diode performance and possible loss in performance will be monitored during the life of the lasercom experiment. It is certain that sensors should be built into the transceiver hardware, but it is not yet certain how many and at what specific locations. The next section discusses the required receiver sensitivity, link calculations, and losses and parameters that need to be specified to perform these calculations.

\section{COMMUNICATION SYSTEM ANALYSIS}

\section{Sensitivity of ACTS/Airborne Direct Detection Receivers}

In this section required receiver sensitivity will be determined for the ACTS and aircraft optical communication receivers. Receiver sensitivity is defined here to be the average signal power that must be incident on the photodetector in order to achieve a given bit error rate (BER). Although sensitivities will be computed only for binary pulse positicn modulation (BPPM), the equations to be presented can also be used to analyze the general M-ary PPM case.

A model of the direct detection receiver using an avanlanche photodiode $(A P D)$ is shown in figure 4. Here, the desired optical signal along with background radiation is collected and focused by the receiving optics onto the depletion region of a reverse-biased APD. An optical filter is placed in front of the detector to reduce the amount of background power. Photons incident on the APD with energy greater than or equal to the band gap energy of the detector material are absorbed, thus producing free electron-hole pairs. These primary photocarriers are accelerated by a high electric field that exists in the $A P D$, and they, in turn, generate more photocarriers through impact ionization. Thus an avalanche process occurs within the APD with each primary carrier undergoing a multiplication that is statistical in nature with mean gain $G$. The signal input to the decision block will have a desired signal component, a background noise component, and noise components due to the photoelectron and amplifier circuitry. These include:

(1) Quantum or shot noise arising from the random nature of the photon-toelectron conversion process

(2) Bulk dark current noise arising from the thermal generation of photocarriers in the pn junction of the APD

(3) Surface dark current noise that is dependent on surface defects, cleanliness, bias voltage, and surface area

(4) Thermal noise due to the amplifier load resistance

(5) Avalanche gain noise due to the statistical nature of the avalanche process and the fact that not all photocarriers undergo the same multiplication

The decision block of the receiver employs a MAP (maximum a posteriori) decoding strategy wherein the detector output current is integrated over each PPM time slot, and the slot with the maximum photoelectron count is assumed to 
be the one in which the signal pulse was transmitted. Once the position of the pulse within the PPM word has been decided, output of the corresponding data bits is straight-forward.

In general, receiver sensitivity is a function of the PPM order, bit rate, amount of interfering background power, and performance parameters characterizing the APD and its associated receiver circuitry. The steps needed to calculated required sensitivity are outlined below. Equations were developed from information in references 3 to 6 inclusive. from:

Step 1. The PPM time slot duration (integration period) is calculated

$$
\tau=\frac{\log _{2} M}{M R_{B}} \sec
$$

where

M PPM order or time slots per word $\left(\log _{2} M\right.$ bits of information are contained in each PPM word)

$R_{B}$ data rate (bps)

Step 2. The amount of the background power incident on APD is:

$$
P_{B}=\frac{\pi n_{R} D_{R}^{2 \theta} R^{2}}{16} \Delta \lambda W(\lambda) \text { watts }
$$

where

$n_{R} \quad$ receiver optics efficiency

$D_{R} \quad$ receiver aperture diameter, $\mathrm{cm}$

$\theta_{R} \quad$ planar angle receiver field of view (FOV), rad

$\Delta \lambda \quad$ the receiver filter optical bandwidth, $\mu$

$W(\lambda)$ spectral radiant emittance of background source, $W / \mathrm{cm}^{2}-\mu$

The equation above is for an extended background source that covers the entire receiver FOV. This will always be the case for the background sources considered here, since the background radiation due to "contained" sources such as stars and and planets was found to be negligible in comparison to other noise components. Once background power has been calculated, the average number of background counts/sec and counts/slot can be found from:

$$
\begin{gathered}
N_{B}=\frac{n_{Q} P_{B}}{h_{\nu}} \text { counts/sec } \\
K_{B}=N_{B} \tau \text { background counts/slot }
\end{gathered}
$$


where

h Planck's constant $(6.62 \mathrm{e}-34 \mathrm{~J}-\mathrm{sec})$

$\checkmark$ frequency of radiation, $\sec ^{-1}$

$\mathrm{n}_{\mathrm{Q}}$ detector quantum efficiency (photoelectrons/photon)

Table I shows the background count rates for the ACTS/LCS (Laser Communication Subsystem) and AIR direct detection receivers under different background environments. For the AIR receiver aperture size, a value of $30 \mathrm{~cm}$ ( 11.8 in.) was used in the calculation since it represents the maximum diameter of a practical sized telescope to be mounted on the aircraft. These background count rates will be used later on in calculating receiver sensitivities.

Step 3. The mean of the detector thermal noise is zero, and the variance is:

$$
K_{t h}{ }^{2}=\frac{2 K_{b} S^{\tau}}{R_{L} q^{2}} \text { counts }^{2}
$$

where

Kb Boltzmann's constant $(1.38 \mathrm{e}-23 \mathrm{~J} / \mathrm{K})$

Ts receiver equivalent noise temperature, $K$

$R_{L}$ detector load resistance, $\Omega$

q electron charge (1.602e-19 coulomb)

Step 4. The primary photoelectron counts/slot due to the APD bulk dark current and surface leakage current are:

$$
\begin{aligned}
& K_{D C B}=\frac{I_{B} \tau}{q} \text { counts/slot } \\
& K_{D C S}=\frac{I_{S} \tau}{q} \text { counts/slot }
\end{aligned}
$$

where

IB gain dependent bulk dark current, $A$

Is gain independent surface dark current, $A$

Step 5. The APD output can be effectively approximated using Gaussian statistics. Hence, for a time slot with no optical signal pulse, the probability density function describing the number of counts/siot is:

$$
f_{0}(x)=\frac{1}{\sqrt{2 \pi} \sigma_{0}} e^{-\left(x-\mu_{0}\right)^{2} / 2 \sigma_{0}^{2}}
$$


where

$$
\begin{gathered}
\mu_{0}=G\left(m K_{S}+K_{B}+K_{D C B}\right)+K_{D C S} \\
\sigma_{0}^{2}=G^{2} F\left(m K_{S}+K_{B}+K_{D C B}\right)+K_{D C S}+K_{t h}^{2}
\end{gathered}
$$

$\mu_{0} \quad$ mean photoelectron count in a nonsignal slot

$\sigma_{0}^{2}$ variance of the photoelectron count in nonsignal slot

G APD mean gain

$m$ transmit laser modulation extinction ratio (ratio of intensity of "off" state to intensity in "on" state)

F APD excess noise factor (due to random avalanche yain)

$\mathrm{K}_{\mathrm{S}}$ photoelectron count due to the desired signal

Similarly, for a time slot with the optical signal pulse, the density function is:

$$
f_{1}(x)=\frac{1}{\sqrt{2 \pi} \sigma_{1}} e^{-\left(x-\mu_{1}\right)^{2} / 2 \sigma_{1}^{2}}
$$

where

$$
\begin{gathered}
\mu_{1}=G\left(K_{S}+K_{B}+K_{D C B}\right)+K_{D C S} \\
\sigma_{1}^{2}=G^{2} F\left(K_{S}+K_{B}+K_{D C B}\right)+K_{D C S}+K_{t h}{ }^{2}
\end{gathered}
$$

$\mu_{1}$ mean photoelectron count in a signal slot

$\sigma_{1}^{2}$ variance of the photoelectron count in signal slot

Step 6. Given that there are $m$ time slots in an M-ary PPM word and that only one of the time slots contains the optical signal pulse, the probability of making a correct decision on the PPM word will be equal to the probability that the photoelectron count in the signal slot is greater than the count in any of the remaining $M-1$ nonsignal slots. Thus the probability of choosing the correct word is:

$$
\begin{gathered}
\text { PWC }=\int_{-\infty}^{\infty} \frac{1}{\sqrt{2 \pi} \sigma_{1}} e^{-\left(x-\mu_{1}\right)^{2} / 2 \sigma_{1}{ }^{2}\left[\int_{-\infty}^{x} \frac{1}{\sqrt{2 \pi} \sigma_{0}} e^{-\left(y-\mu_{0}\right)^{2} / 2 \sigma_{0}^{2}} d y\right]^{M-1} d x} \\
=\int_{-\infty}^{\infty} \frac{1}{\sqrt{2 \pi} \sigma_{1}} e^{-\left(x-\mu_{1}\right)^{2} / 2 \sigma_{1}^{2}}\left[\operatorname{Erf}\left[\frac{x-\mu_{0}}{\sigma_{0}}\right]\right]^{M-1} d x
\end{gathered}
$$


where

$\operatorname{Erf}(x)$ "communications" error function defined here as:

$$
\operatorname{Erf}(x)=\int_{-\infty}^{x} \frac{1}{\sqrt{2 \pi}} e^{-z^{2} / 2} d z=\operatorname{Prob}(x \leqq x)
$$

Note that this definition is different from the "statistical" error function defined by:

$$
\operatorname{erf}(x)=\int_{0}^{x} \frac{2}{\sqrt{\pi}} e^{-z^{2}} d z
$$

The two are related by the equations:

$$
\operatorname{Erf}(x)=\frac{1}{2}+\frac{1}{2} \operatorname{erf}\left(\frac{x}{\sqrt{2}}\right)
$$

or

$$
\operatorname{erf}(x)=2 \operatorname{Erf}(\sqrt{2} x)-1
$$

Once we have PWC, the average bit error rate can be written as:

$$
B E R=\frac{M}{2(M-1)}(1-P W C)
$$

Step 7. For the case of BPPM $(M=2)$, equation (19) can be rewritten if we define the SNR of the APD-based PPM receiver to be:

$$
\operatorname{SNR}=\frac{\mu_{1}-\mu_{0}^{2}}{\sigma_{0}^{2}+\sigma_{1}^{2}}
$$

Substituting for $\mu_{1}, \mu_{0}, \sigma_{1}$, and $\sigma_{0}$ we have:

$$
S N R=\frac{G^{2} K_{S}{ }^{2}(m-1)^{2}}{G^{2} F\left[K_{S}(m+1)+2\left(K_{B}+K_{D C B}\right)\right]+2\left(K_{C C S}+K_{t h}{ }^{2}\right)}
$$

Then (19) can be expressed as:

$$
B P P M B E R=\frac{1}{2} \operatorname{erfc}\left(\sqrt{\frac{S N R}{2}}\right)
$$

where

$\operatorname{erfc}(x)=1-\operatorname{erf}(x)$ is the "statistical" complementary error function 
Step 8. Using equation (19) for $M>2$ or equation (22) for $M=2$, let $K_{S}$, the desired signal counts/pulse, vary and compute the resulting BER for the given data rate, background power, and APD parameters. The required $K_{s}$ to achieve a desired BER can then be determined. Once the target $K_{S}$ is known, the target signal counts/bit, photons/bit, and photons/sec can be found from:

$$
\begin{gathered}
C_{s}=\frac{K_{S}}{\log _{2} M} \text { counts/bit } \\
P_{S}=\frac{C_{s}}{n_{Q}} \text { photons/bit } \\
\lambda_{S}=P_{S} R_{B} \text { photons/sec }
\end{gathered}
$$

Finally, the required average signal power that must be incident on the APD to achieve the desired BER is simply given by:

$$
P_{R}=\lambda_{S} h v \text { watts }
$$

This is, be definition, the required receiver sensitivity. The difference between the actual received power and this required power is the link margin.

Using the steps outlined above, plots of BPPM BER as a funciton of required signal counts/bit were constructed for the ACT/LCS and AIR direct detection receivers under different background operating conditions ( $f i g s .5$ to 8). Since specific parameters describing the DDLT (Direct Detection Laser Transceiver) Si-APD on the ACTS were not available at the time of this writing, typical values for a commercially available device were assumed. These are shown in table II. This same set of APD parameters was also used for the AIR APD. Curves were generated for each of the data rates at which the laser links might operate. From the curves, one observes that, for a particular BER, fewer signal counts/bit are required as the data rate increases. This is due to the fact that at higher data rates, slot times are narrower and less thermal, background, and dark current noise counts occur within each slot; hence, fewer signal counts/slot are needed to maintain the same BER. What is not evident from the plots is that higher peak laser power is required to maintain the same signal counts/slot as data rate increases. For example, doubling the data rate cuts the slot interval by half, and thus to maintain the same signal counts/slot required twice the peak power.

Table III is a summary of the plot information showing the required signal counts/bit and corresponding required power (in dbW) for error rates of $10 \mathrm{e}-3,10 \mathrm{e}-6$, and $10 \mathrm{e}-8$. It can be seen that communication with the airborne terminal with the sun in its receive FOV is impractical. Also, the presence of a dark earth in the ACTS FOV introduces negligible background radiation. The required powers shown in the table will be used in the next section for calculating link margins.

\section{Communications Link Analysis}

In this section, actual receive power will be calculated for both the forward link (ACTS-to-AIR) and return link (AIR-to-ACTS) and compared with 
required power to estimate the amount of link margin at the various data rates with different airborne terminal aperture sizes.

$$
P_{R}=P_{T}{ }^{\eta_{T}} T_{R} G_{T} G_{R} L_{p}\left[\frac{\lambda}{4 \pi Z}\right]^{2} L_{A} L_{\text {OTHER }} \text { watts }
$$

where

$P_{R} \quad$ average received power, $W$

$P_{T} \quad$ average transmitted power, $W$

${ }^{n_{T}} \quad$ transmit optics efficiency

$n_{R} \quad$ receive optics efficiency

$\mathrm{GT}_{T}$ gain of the transmitter optics

$G_{R}$ gain of the receiver optics

$L_{p} \quad$ pointing loss

$Z$ range

$\lambda \quad$ wavelength of source

LA atmospheric loss

LOTHER other losses such as source laser beam combining loss, secondary mirror obscuration losses (in Cassegrainian telescopes), and communication/tracking power split losses

The transmit and receive optics gains can be related to their aperture size and wavelength by:

$$
G_{T}=\left[\frac{D_{T} \pi}{\lambda}\right]^{2}=\frac{4 \pi}{\Omega_{T}} \text { numeric gain }
$$

and

$$
G_{R}=\left[\frac{D_{R} \pi}{\lambda}\right]^{2}=\frac{4 \pi}{\Omega_{R}} \text { numeric gain }
$$

where

$D_{T}$ transmit aperture diameter, $m$

$D_{R}$ receive aperture diameter, $m$

$\Omega_{T} \quad$ solid angle into which the xmit signal is radiated, sr

$\Omega_{R}$ solid angle into which the recv signal is concentrated, sr 
The pointing loss associated with an angular pointing error, $\theta$, from $x m i t / r e c v$ line-of-sight (LOS) is given by:

$$
L_{p}=\left[\frac{2 J_{1}(\pi \ominus D / \lambda)}{\pi \ominus D / \lambda}\right]^{2}
$$

where

$L_{p} \quad x m i t / r e c v$ pointing loss (numeric)

$\theta \quad x m i t / r e c v$ angular pointing error, rad

$3_{1}$ () denotes the first order Bessel function

D $\quad x m i t / r e c v$ aperture diameter, m

Received power can then be converted to received signal counts/bit by:

$$
C_{S}=P_{R} \frac{{ }^{n} Q}{R_{B} h_{\nu}} \text { counts/bit }
$$

Using the equations above and the link parameters shown in table IV for the ACTS-to-AIR and AIR-to-ACTS links, a parametric analysis was performed to determine the effect of aircraft aperture size on the link performance.

Figure 9 shows a plot of received signal counts/bit versus aircraft aperture diameter for the forward ACTS-to-AIR link. A single CW $30 \mathrm{~mW}$ laser is assumed to be operating on the ACTS with transmission through a $20 \mathrm{~cm}$ (7.9 in.) aperture. Figure 10 shows a similar plot for the reture AIR-to-ACTS link with a single $\mathrm{CW} 50 \mathrm{~mW}$ laser source aboard the aircraft.

Table $V$ shows received counts/bit and received average power (dbW) for aircraft aperture sizes of $10,15,20,25$, and $30 \mathrm{~cm}(3.9,5.9,7.9,9.8$, and 11.8 in.). By comparing the actual received power (or signal counts/bit) shown in table $V$ with the required power (or signal counts/bit) shown in table III, the amount of margin obtainable for various combinations of BER, data rate, background environment, and aircraft aperture size can be determined. This is shown in table VI, where each of the link margin entries was calculated by subtracting the required power (for the BER, data rate, and background condition in question) from the corresponding actual received power listed in table $V$. From the link margin table, it is apparent that the forward ACTS-to-AIRCRAFT link is the more constraining of the two. Also, substantially greater margins can be realized if communications occur at night when the amount of interfering background radiation is reduced. In almost all cases, the performance of the forward link at the maximum data rate of 220 Mbps is unacceptable using the single $30 \mathrm{~mW}$ GaAs laser planned on the ACTS. In fact, the only condition that yields a margin greater than $3 \mathrm{db}$ at $220 \mathrm{Mbps}$ is a $30 \mathrm{~cm}$ aperture on the aircraft and 10-3 BER. For optics size in the range of 15 to $20 \mathrm{~cm}$ and 10-6 BER, operation at 27.5 Mbps gives only about 2 to $5 \mathrm{db}$ of margin on the ACTSto-AIR link. If the data rate is reduced to $1.72 \mathrm{Mbps}$, then 10 to $12 \mathrm{db}$ margin is available.

To increase the amount of margin on the forward link at the higher data rates, receiver sensitivities were recomputed using a lower noise APD on the aircraft. This APD was assumed to have an effective hole-electron ionization 
ratio ( $k_{e f f}$ ) of 0.007 , representative of developmental silicon devices. In addition, for a given desired signal count $K_{S}$, APD gain was computed to maximize the detector SNR in equation (21). Optimum gain càn be found by differentiating equation (21) with respect to $G$, setting the result equal to zero, and solving for $G$. By using the fact that the excess noise factor $F$ is related to the APD gain $G$ and hole-electron ionization ratio keff by,

$$
F=k_{e f f} G+\left(1-k_{e f f}\right)\left(2-\frac{1}{G}\right)
$$

the optimum APD gain can be approximated by,

$$
G_{\text {opt }}=\left[\frac{8 K_{b} T_{s}}{R_{L} q^{2} K_{e f f} K_{S}}\right]^{1 / 3}, K_{D C S} \text { and } K_{D C B} \ll K_{t h}{ }^{2}
$$

Table VII shows a comparison of the aircraft receiver sensitivity between the lower noise, optimum gain APD and the APD used earlier (no background radiation is present). Unfortunately, even with the lower noise APD, detection sensitivity is improved by less than $0.5 \mathrm{db}$ for $10-6$ BER at 55,110 , or $220 \mathrm{Mbps}$. Signal shot noise and avalanche gain noise limits the SNR at these higher data rates. Thus, a higher output laser (or laser beam combining) is required on the ACTS to improve the link margin.

\section{ACQUISITION}

For the ACTS/AIRCRAFT lasercom experiment, it is not necessary for NASA Lewis to develop an acquisition procedure, as this procedure has been established by the design of the laser communication package on-board ACTS. The acquisition hardware and software is currently being designed and implemented by MIT's Lincoln Labs as part of their heterodyne lasercom effort. Thus, experiments such as the NASA Lewis ACTS to aircraft laser link need only to implement an acquisition system compatible with that on the ACTS. LL as the originator of this design will report on their effort as appropriate. It is sufficient here to give a brief description of the anticipated acquisition procedure sequence.

\section{Acquisition will occur as follows:}

(1) First, each terminal, ACTS and the aircraft, must receive location data for the other terminal and then generate a "most probable direction" for aiming their acquisition optics.

(2) The satellite transmits an acquisition beacon, spread out to a $1 \mathrm{mrad}$ beamwidth.

(3) If the "most probable direction" has been sufficiently accurate, the airborne terminal will acquire the ACTS beacon and then transmit a beam of its own back to the satellite. If acquisition does not occur on the first attempt, the I mrad beam is moved to other locations adjacent to the initial "most probable" until acquisition does occur. 
(4) The ACTS detector acquires the beacon from the airborne unit, and after this has occurred, both laser packages perform the internal adjustments necessary for initiation of fine tracking.

(5) The airborne terminal must continue to transmit its beacon in order that ACTS can maintain tracking of the aircraft. Once communication is initiated, the ACTS beam is reduced to a beamwidth of $4 \mathrm{mrad}$.

Reference 2 describes a suitable acquisition array, gives it characteristics, and includes acquisition link calculations that are based on these characteristics.

\section{CONCLUSIONS}

The calculations described above indicate that even with the constraint of the $30 \mathrm{~mW}$ output power of the ACTS direct detection laser transmitter, judicious choice of aperture size, aircraft receiver, and data rate makes feasible an ACTS to aircraft direct detection laser communication experiment. Acquisition and tracking issues have not been addressed in this paper but work performed at Lincoln Labs, Goddard Space Flight Center, and Wright-Patterson AFB indicate that this is also feasible. At the time of this writing, sufficient details about the ACTS laser communication package are rot known, so a more specific experiment $p l a n$ and hardware definition than that presented herein cannot yet be developed. The follow-on effort to this paper will be to resolve specific design details of the airborne transceiver as the definition of the ACTS laser communication package becomes final.

\section{REFERENCES}

1. R.J. Feldman, "Feasibility Analys is of An Air-to-Satellite Laser Communications Link," in National Aerospace Electronics Conference, Vol. 3 pp. $1102-1109,1987$.

2. "Preliminary Execution Phase Project Plan Laser Intersatellite Link Advanced Communications Technology Spacecraft," Goddard Space Flight Center, Greenbelt, MD, Aug. 1985.

3. G. Keiser, Optical Fiber Communications, pp. 145-167, MCGraw-Hill, New York (1983).

4. J.B. Abshire, "Performance of OOK and Low-Order PPM Modulations in Optical Communications When Using APD-Based Receivers," IEEE Trans. Commun., Com-32 (10), $1140(1984)$.

5 C.C. Chen, and C.S. Gardner, "Comparison of Direct and Heterodyne Optical Intersatellite Communication Links, "NASA CR-180210, 1987.

6. R.M. Gagliardi and G. Prati, "On Gaussian Error Probabilities in Optical Receivers," IEEE Trans. Commun., Com-28 (9) 1742 (1980).

7. M.J. Windmiller, "Unique Bit-Error-Rate Measurement System for Satellite Communication Systems," NASA TP-2699, 1987. 
Table 1. Receiver Background Count Rates for Selected Sources in the FOV

\begin{tabular}{|c|c|c|c|c|c|c|c|c|c|c|}
\hline & & $\begin{array}{l}\text { RMDUNCE } \\
\text { WATTS } \\
\mathrm{CM}^{2}-\text { MOAON }\end{array}$ & $\begin{array}{l}\text { FECr OPHCS } \\
\text { EFPCIENCY }\end{array}$ & $\begin{array}{l}\text { PECV OPTCS } \\
\text { SIIE (ON) }\end{array}$ & $\begin{array}{l}\text { RECV FOV } \\
\text { (MICAOANOS ) }\end{array}$ & $\begin{array}{l}\text { OPTICN } \\
\text { FUTER EW } \\
\text { (MICAONS) }\end{array}$ & $\begin{array}{l}\text { WAVELENGTH } \\
\text { (MMCAONS ) }\end{array}$ & OLANTUM EFF & $\begin{array}{c}\text { BACKGAOUND } \\
\text { POWER } \\
\text { (WATS') }\end{array}$ & $\begin{array}{l}\text { BACKGAOUND } \\
\text { COUNT RATE } \\
\text { COUNTS/SEC }\end{array}$ \\
\hline \multirow{3}{*}{ 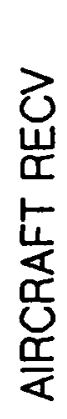 } & $\begin{array}{l}\text { SUNLIT } \\
\text { SKY IN } \\
\text { FOV }\end{array}$ & 20 & $35 \%$ & 30 & 100 & $2.0 E-3$ & .870 & $70 \%$ & 2.47E-8 & 7.6E10 \\
\hline & $\begin{array}{l}\text { SUN IN } \\
\text { FOV }\end{array}$ & 2000 & $35 \%$ & 30 & 100 & $2.0 E-3$ & .870 & $70 \%$ & $2.47 E-6$ & $7.6 \mathrm{E} 12$ \\
\hline & $\begin{array}{c}\text { MOON IN } \\
\text { FOV }\end{array}$ & $3.0 \mathrm{E}-3$ & $35 \%$ & 30 & 100 & $2.0 E-3$ & .870 & $70 \%$ & 3.71E-12 & 1.1E7 \\
\hline \multirow{3}{*}{ 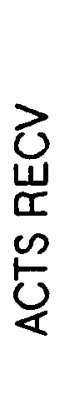 } & $\begin{array}{l}\text { SUNUT } \\
\text { COOND } \\
\text { CONERED } \\
\text { EAPTH }\end{array}$ & $1.0 E-1$ & $60 \%$ & 20 & 100 & $1.6 \mathrm{E}-2$ & .840 & $70 \%$ & $7.53 E-10$ & 2.2E9 \\
\hline & $\begin{array}{l}\text { MmuT } \\
\text { GEA } \\
\text { ENATH }\end{array}$ & $1.0 E-2$ & $60 \%$ & 20 & 100 & $1.6 \mathrm{E}-2$ & .840 & $70 \%$ & 7.53E-11 & $2.2 E 8$ \\
\hline & $\begin{array}{l}\text { DARK } \\
\text { EARTH }\end{array}$ & $1.0 E-3$ & $60 \%$ & 20 & 100 & $1.6 E-2$ & .840 & $70 \%$ & $7.53 E-12$ & $2.2 E 7$ \\
\hline
\end{tabular}

Table 2. Typical Si-APD Based Direct Detection Receiver Parameters

\begin{tabular}{|l|l|l|}
\hline QUANTUM EFFICIENCY & $\eta_{0}$ & $70 \%$ \\
EFFECTIVE HOLE-TO-ELECTRON IONIZATION RATIO & $\mathrm{k}_{\text {eff }}$ & 0.01 \\
AVERAGE DETECTOR GAIN & $\mathrm{G}$ & 150 \\
EXCESS NOISE FACTOR & $\mathrm{F}$ & 3.5 \\
GAIN DEPENDENT BULK LEAKAGE CURRENT & $\mathrm{I}_{B}$ & $0.1 \mathrm{nA}$ \\
GAIN INDEPENDENT SURFACE LEAKAGE CURRENT & $\mathrm{I}_{S}$ & $10.0 \mathrm{nA}$ \\
EQUIVALENT NOISE TEMPERATURE & $T_{S}$ & $400 \% \mathrm{~K}$ \\
LOAD RESISTANCE & $\mathrm{R}_{\mathrm{S}}$ & $2000 \mathrm{n}$ \\
\hline
\end{tabular}


Table 3. Required Sensitivities for Aircraft and ACTS Receivers

\begin{tabular}{|c|c|c|c|c|c|c|c|c|c|c|c|c|c|c|c|c|}
\hline \multirow{3}{*}{\multicolumn{2}{|c|}{$\begin{array}{l}\text { SIGNAL } \\
\text { COUNTSAIT } \\
\text { PEQUIRED } \\
\text { POWER GOOW }\end{array}$}} & \multicolumn{5}{|c|}{ 10-3 BEA } & \multicolumn{5}{|c|}{ 10-6 BEA } & \multicolumn{5}{|c|}{ 10-8 BEF } \\
\hline & & \multicolumn{5}{|c|}{ DATA RATE MOPS } & \multicolumn{5}{|c|}{ DATA RATE MODS } & \multicolumn{5}{|c|}{ DATA RATE MDPS } \\
\hline & & 1.72 & 27.5 & 55 & 110 & 220 & 1.72 & 27.5 & 55 & 110 & 220 & 1.72 & 27.5 & 55 & 110 & 220 \\
\hline$\sum_{\overline{0}}$ & 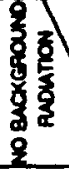 & $\begin{array}{l}290 \\
-. .87 \\
-97.88\end{array}$ & $\begin{array}{c}90 \\
-90.93\end{array}$ & $\begin{array}{c}70 \\
- \\
- \\
89.0\end{array}$ & $\begin{array}{l}60 \\
- \\
86.6\end{array}$ & 84.45 & $\begin{array}{c}460 \\
--95.88\end{array}$ & -88.43 & $\begin{array}{c}130 \\
-.- \\
-86.38\end{array}$ & $\begin{array}{c}110 \\
--- \\
-84.04\end{array}$ & $\begin{array}{l}100 \\
-81.44\end{array}$ & $\begin{array}{c}560 \\
-95.03\end{array}$ & $\begin{array}{l}200 \\
-87.46\end{array}$ & $\begin{array}{c}170 \\
--85.15\end{array}$ & $\begin{array}{c}150 \\
-82.69\end{array}$ & $\begin{array}{c}140 \\
---- \\
-79.98\end{array}$ \\
\hline $\begin{array}{l}\text { 总 } \\
\text { 忌 } \\
\text { 要 }\end{array}$ & 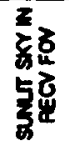 & \begin{tabular}{l}
1310 \\
\hdashline 91.39
\end{tabular} & $\begin{array}{c}350 \\
-85.03\end{array}$ & $\begin{array}{l}250 \\
-.-2 \\
-83.4\end{array}$ & 70 & 130 & $\begin{array}{r}2050 \\
-89.39\end{array}$ & $\begin{array}{r}550 \\
-83.07\end{array}$ & $\begin{array}{l}390 \\
--81.55\end{array}$ & $\begin{array}{r}290 \\
-79.8\end{array}$ & $\begin{array}{c}230 \\
-7.82 \\
-7 .\end{array}$ & $\begin{array}{l}2430 \\
--88.65\end{array}$ & $\begin{array}{c}650 \\
-.-- \\
-82.34\end{array}$ & $\begin{array}{c}490 \\
-80.56\end{array}$ & $\begin{array}{c}370 \\
-78.7\end{array}$ & $\begin{array}{c}290 \\
--- \\
-76.81\end{array}$ \\
\hline $\begin{array}{l}\text { 总 } \\
\text { 䍃 }\end{array}$ & 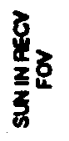 & $\begin{array}{r}12700 \\
--- \\
-81.47\end{array}$ & $\begin{array}{l}3200 \\
-75.42\end{array}$ & $\begin{array}{r}2270 \\
--- \\
-73.9\end{array}$ & & & $\begin{array}{l}19600 \\
-79.59\end{array}$ & $\begin{array}{c}4940 \\
-73.53\end{array}$ & $\begin{array}{r}3510 \\
-72.00\end{array}$ & $\begin{array}{l}2490 \\
--- \\
-70.49\end{array}$ & $\begin{array}{l}1770 \\
---1 \\
-68.96\end{array}$ & $\begin{array}{r}23200 \\
--- \\
-78.85\end{array}$ & $\begin{array}{r}5850 \\
--- \\
-72.80\end{array}$ & $\begin{array}{c}4150 \\
--- \\
-71.28\end{array}$ & $\begin{array}{l}2950 \\
-69.75\end{array}$ & $\begin{array}{c}2110 \\
---- \\
-68.19\end{array}$ \\
\hline$E$ & 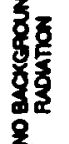 & $\begin{array}{c}290 \\
--- \\
-97.73\end{array}$ & $\begin{array}{c}90 \\
-90.77\end{array}$ & 70 & & & & & $\begin{array}{c}130 \\
--- \\
-86.17\end{array}$ & & $\begin{array}{c}100 \\
-81.29\end{array}$ & $\begin{array}{l}560 \\
-. . \\
-94.87\end{array}$ & $\begin{array}{c}200 \\
-87.31\end{array}$ & $\begin{array}{c}170 \\
--85.00 \\
\end{array}$ & $\begin{array}{c}150 \\
-82.54\end{array}$ & $\begin{array}{c}140 \\
--- \\
-79.83\end{array}$ \\
\hline 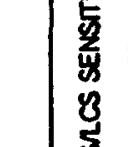 & 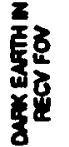 & $\begin{array}{c}290 \\
--.- \\
-97.73\end{array}$ & $\begin{array}{c}90 \\
-90.77\end{array}$ & -88.8 & 86.5 & & $\begin{array}{c}460 \\
-95.73\end{array}$ & -88.28 & $\begin{array}{c}130 \\
-86.17\end{array}$ & $\begin{array}{c}110 \\
--- \\
-83.8\end{array}$ & $\begin{array}{c}100 \\
--81.29\end{array}$ & $\begin{array}{r}560 \\
-94,87\end{array}$ & $\begin{array}{c}200 \\
-87.31\end{array}$ & $\begin{array}{c}170 \\
-85.00 \\
-.-1\end{array}$ & $\begin{array}{c}150 \\
-82.54\end{array}$ & $\begin{array}{c}140 \\
---- \\
-79.83\end{array}$ \\
\hline छ & 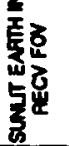 & 360 & no & 80 & $\begin{array}{l}60 \\
-\end{array}$ & $\begin{array}{c}50 \\
-.- \\
84.30\end{array}$ & $\begin{array}{l}580 \\
-94.72\end{array}$ & $\begin{array}{l}180 \\
87.76\end{array}$ & $\begin{array}{c}150 \\
-85.55\end{array}$ & $\begin{array}{c}120 \\
-- \\
-83.5\end{array}$ & $\begin{array}{c}110 \\
\ldots-80.87\end{array}$ & $\begin{array}{c}690 \\
--- \\
-93.97\end{array}$ & 230 & $\begin{array}{r}190 \\
-84.5 \\
-8\end{array}$ & $\begin{array}{c}160 \\
--82.25\end{array}$ & 150 \\
\hline
\end{tabular}


Table 4. ACTS/Aircraft Communication Link Parameters

\begin{tabular}{|c|c|c|c|c|}
\hline PAPAMETER & \multicolumn{2}{|c|}{ ACTS-TO-AIACRAFT } & \multicolumn{2}{|c|}{ AIACAAFT-TO-ACTS } \\
\hline DATA RATES & \multicolumn{2}{|c|}{$1.72,27.5,55,110$, AND 220 MBPS } & \multicolumn{2}{|c|}{$1.72,27.5,55,110$. AND $220 \mathrm{MBPS}$} \\
\hline $\begin{array}{l}\text { MOOULATION } \\
\text { FORMAT }\end{array}$ & \multicolumn{2}{|c|}{ DIRECT DETECTION BPPM } & \multicolumn{2}{|c|}{ DIRECT DETECTION BPPM } \\
\hline $\begin{array}{c}\text { SOUACE } \\
\text { WAVELENGTH }\end{array}$ & \multicolumn{2}{|c|}{.870 MKCAON } & \multicolumn{2}{|c|}{.840 MICAON } \\
\hline $\begin{array}{l}\text { DETECTOR } \\
\text { QUANTUM EFF }\end{array}$ & \multicolumn{2}{|c|}{$B 1-A P D \quad T O *$} & \multicolumn{2}{|l|}{$S I-A P D$} \\
\hline $\begin{array}{l}\text { AVG XMIT } \\
\text { LASER POWER }\end{array}$ & $\begin{array}{l}\text { SINGE } 30 \mathrm{~mW} \\
\text { GaAs laser }\end{array}$ & $-15.23 \mathrm{dbW}$ & $\begin{array}{l}\text { SINGLE 50mW } \\
\text { GaAs laser }\end{array}$ & $-13.01 \mathrm{dbW}$ \\
\hline $\begin{array}{l}\text { XMIT OPTICS } \\
\text { EFFICIENCY }\end{array}$ & $40 \%$ & $-3.98 \mathrm{db}$ & $40 \%$ & $-3.98 \mathrm{db}$ \\
\hline $\begin{array}{l}\text { XMIT DIAMETER } \\
\text { AND GAIN }\end{array}$ & $20 \mathrm{~cm}$ APEATURE & $117.17 \mathrm{db}$ & \multicolumn{2}{|c|}{ PARAMETER TO BE VARIED } \\
\hline POINTING LOSS & $\begin{array}{l}0.5 \text { microrsed rms } \\
\text { pointing error }\end{array}$ & $-1.02 d b$ & $\begin{array}{l}0.5 \text { microrad rms } \\
\text { pointing error }\end{array}$ & $-1.02 d b$ \\
\hline $\begin{array}{c}\text { ATMOSPHERIC LOSS } \\
\text { CLEAR AIR }\end{array}$ & 0.83 & $-0.8 \mathrm{db}$ & 0.83 & $-0.8 \mathrm{db}$ \\
\hline $\begin{array}{c}\text { RANGE/SPACE } \\
\text { LOSS }\end{array}$ & $38070 \mathrm{~km}$ & $-294.81 d b$ & $38070 \mathrm{~km}$ & $-295.11 \mathrm{db}$ \\
\hline $\begin{array}{l}\text { RECV OPTKCS } \\
\text { EFFICIENCY }\end{array}$ & $62 \%$ & $-2.08 d b$ & $62 \%$ & $-2.08 \mathrm{db}$ \\
\hline $\begin{array}{c}\text { RECV DIAMETER } \\
\text { AND GAIN }\end{array}$ & PARAMETEF & E VARIED & $20 \mathrm{~cm}$ APERTURE & $117.48 \mathrm{db}$ \\
\hline
\end{tabular}


Table 5. ACTS/Aircraft Received Power and Signal Counts/Bit vs Aperture Size

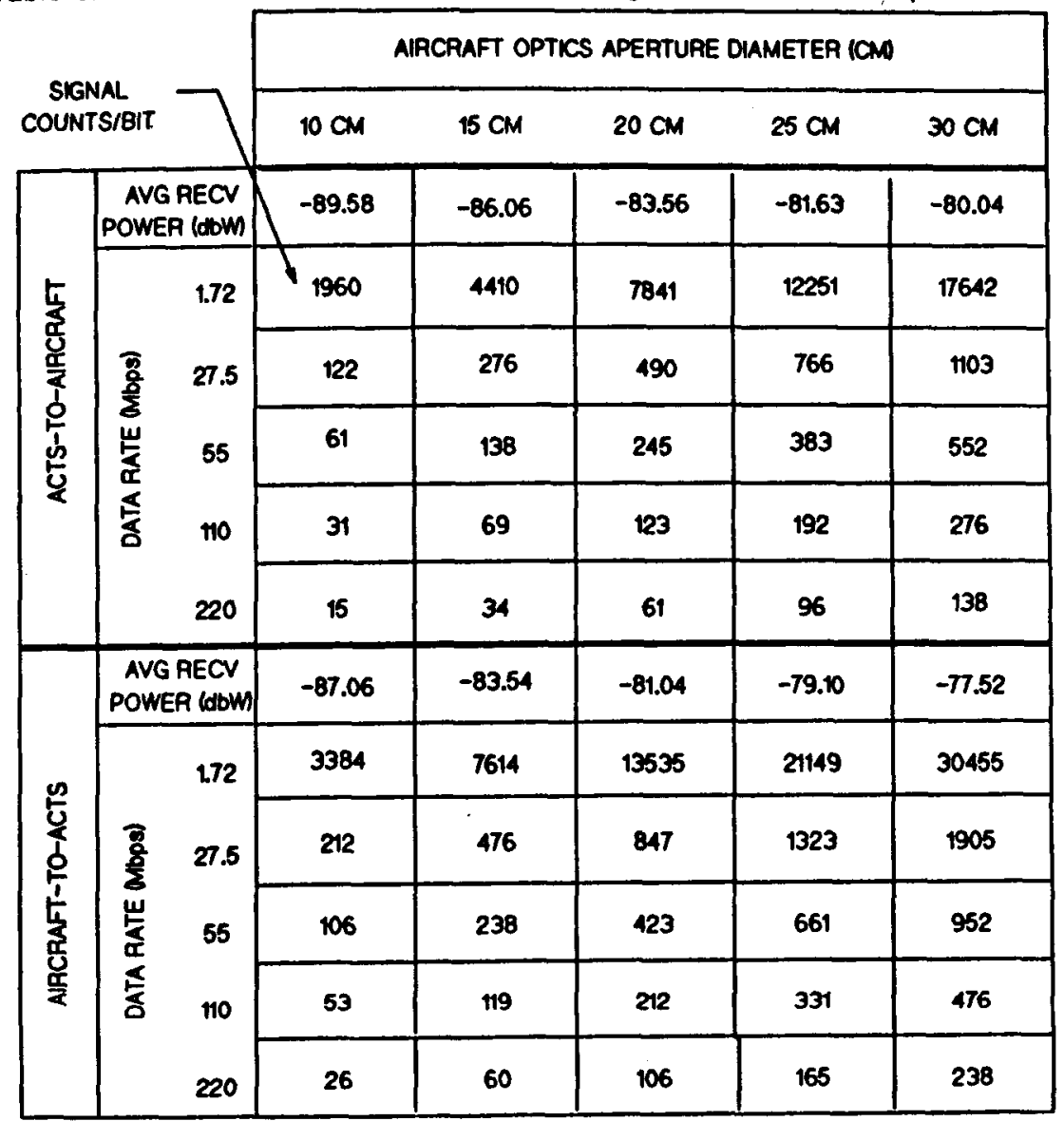


ORIGINAL PAGE IS

OF POOR QUALITY

Table 6. Available ACTS/Aircraft Link Margins

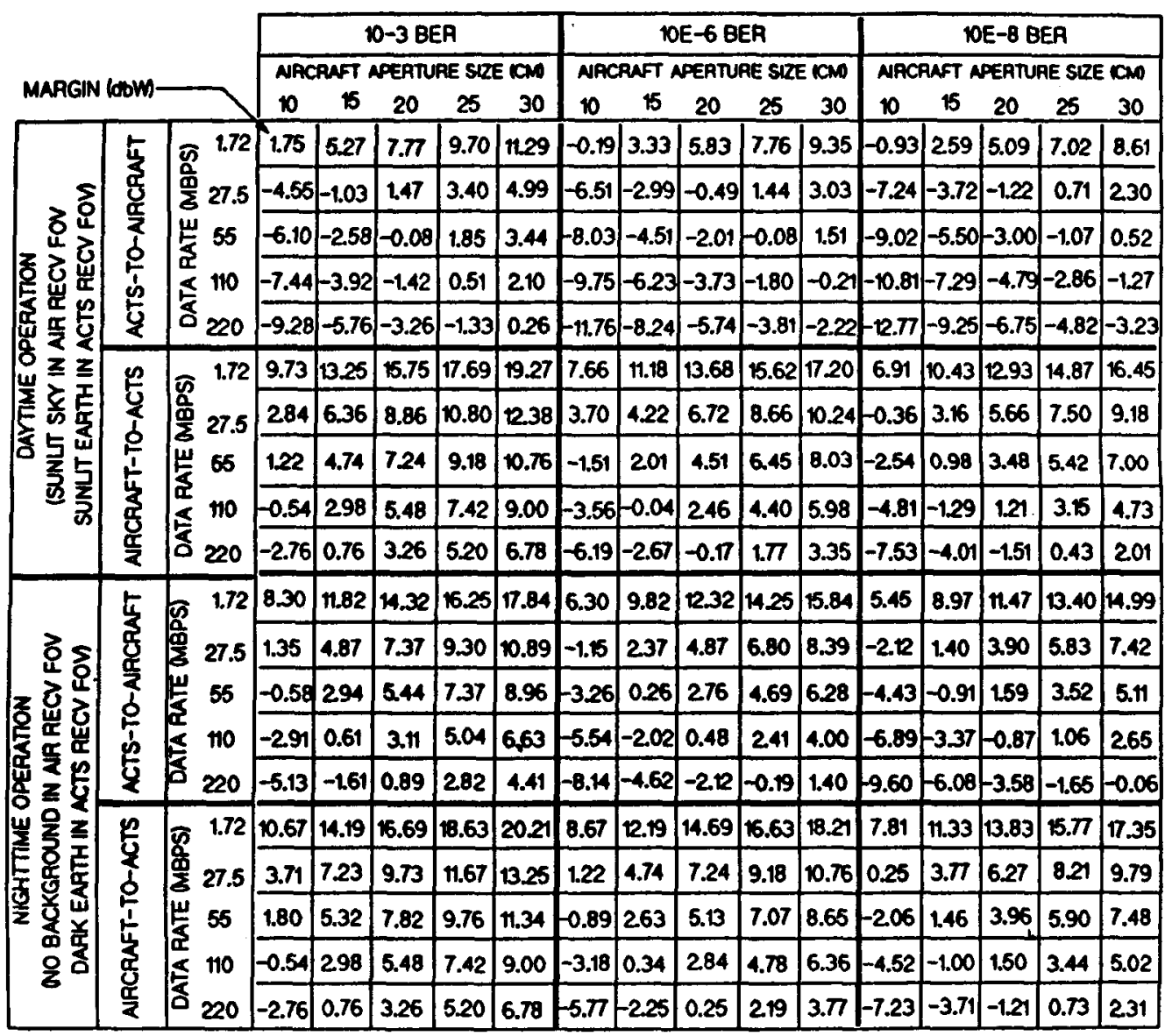


TABLE 7. AIRCRAFT RECEIVER SENSITMITIES WITH TWO DIFFERENT APD'S

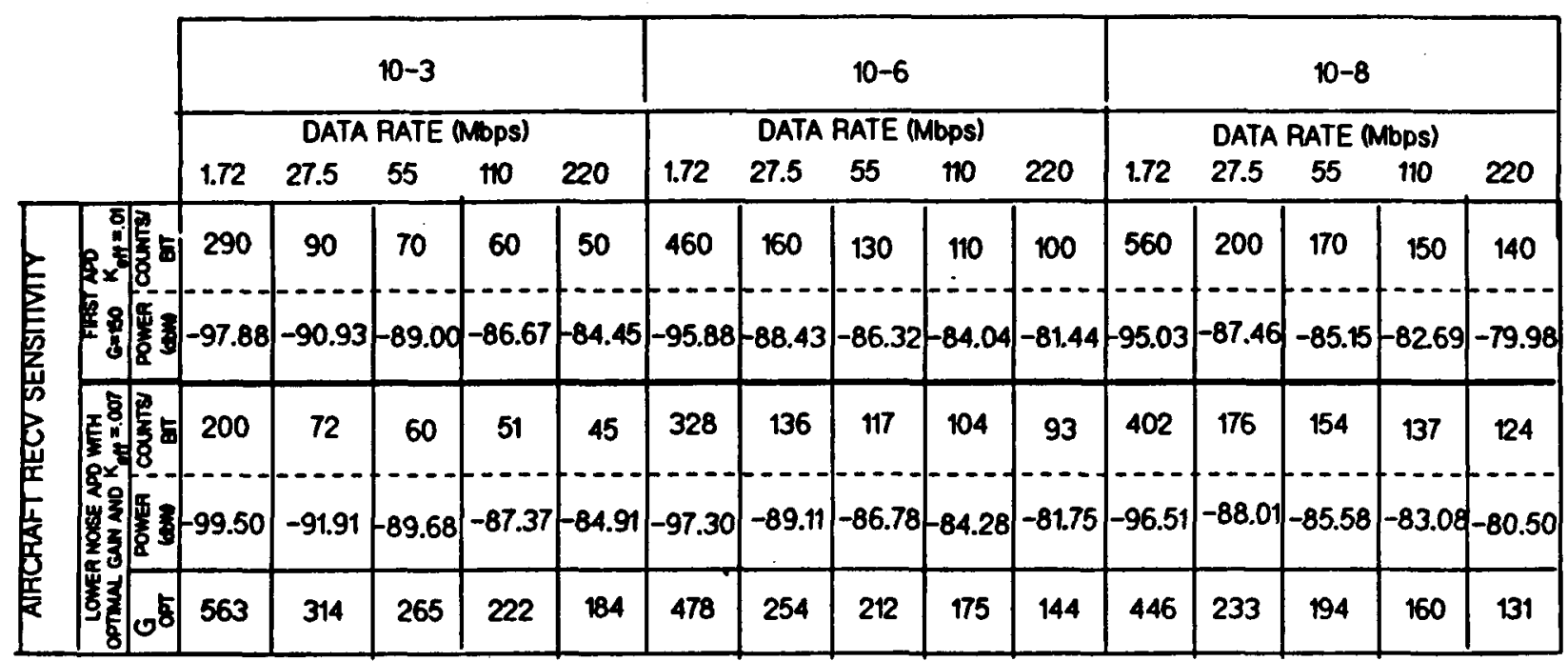

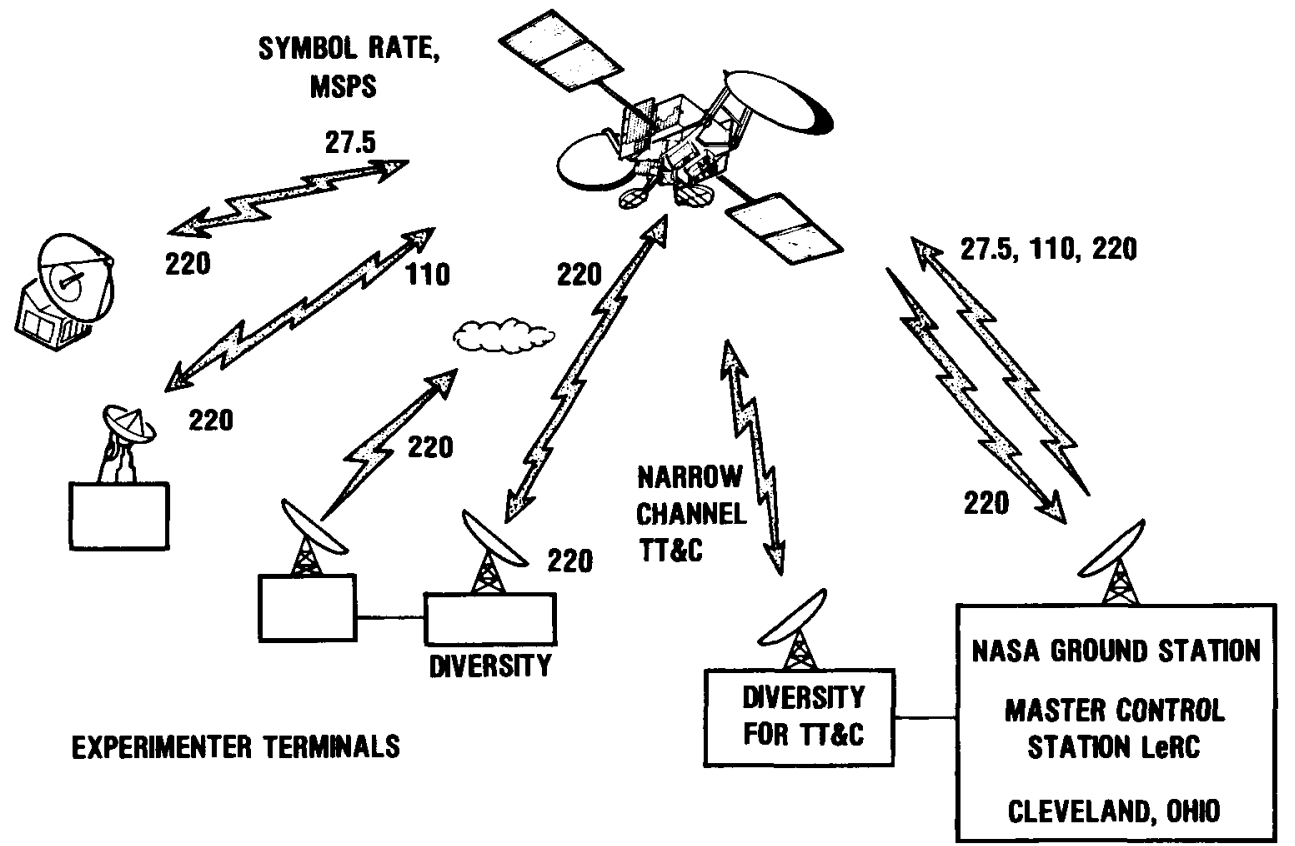

FiguRE 1. - ADVANCED COMMUNICATIONS TECHNOLOGY SATELLITE SYSTEM.

CD-84-15055 


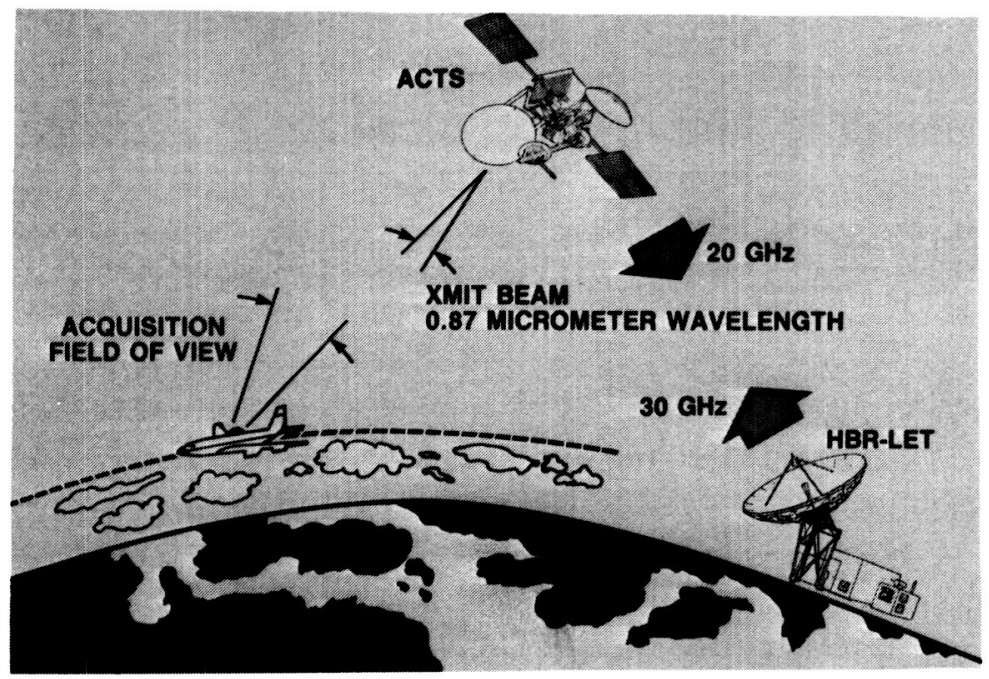

FIGURE 2. - LERC PROPOSED DIRECT DETECTION LASERCOM EXPERIMENT.

ORIGINAL PAGE IS

OF POOR QUALITY

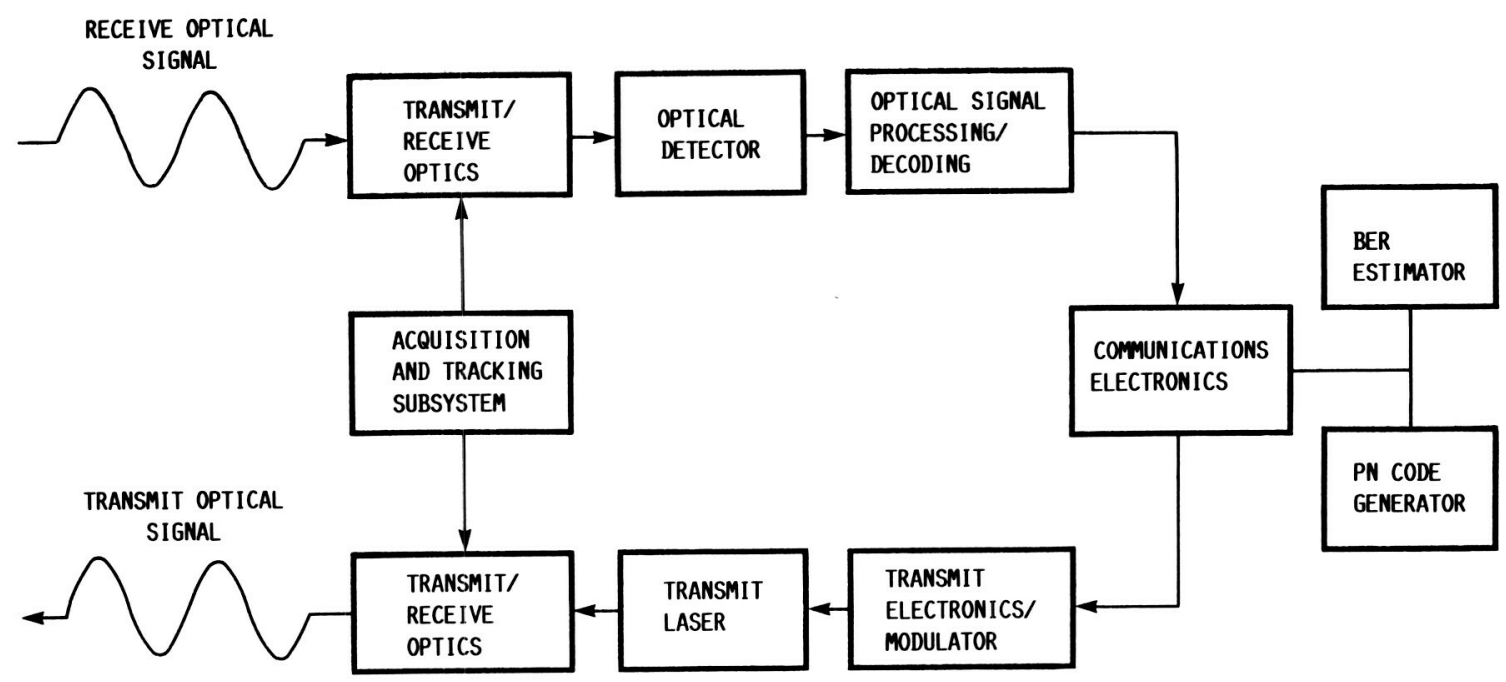

FIGURE 3. - AIRBORNE LASER TRANSCEIVER FUNCTIONAL BLOCK DIAGRAM. 


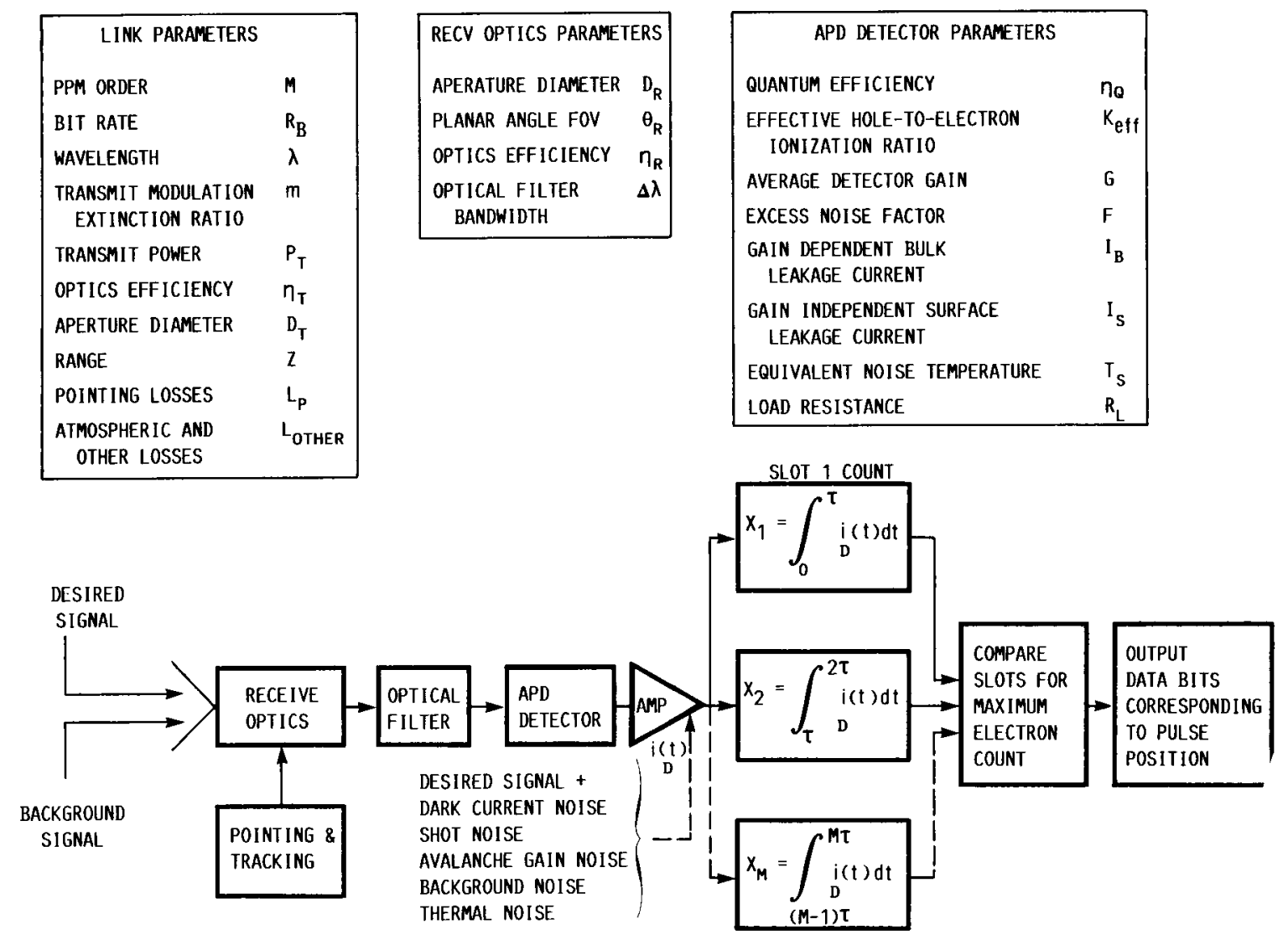

BACKGROUND SIGNAL PARAMETERS

SOURCE DIAMETER (IF ENCLOSED BY RECV FOV) $D_{S}$

RANGE TO RECVR (IF ENCLOSED BY RECV FOV) $z_{S}$

SPECTRAL RADIANT EMITTANCE

$W(\lambda)$

FiguRE 4. - DIRECT DETECTION M-ARY PPM RECEIVER MODEL. AND RELEVANT PARAMETERS.

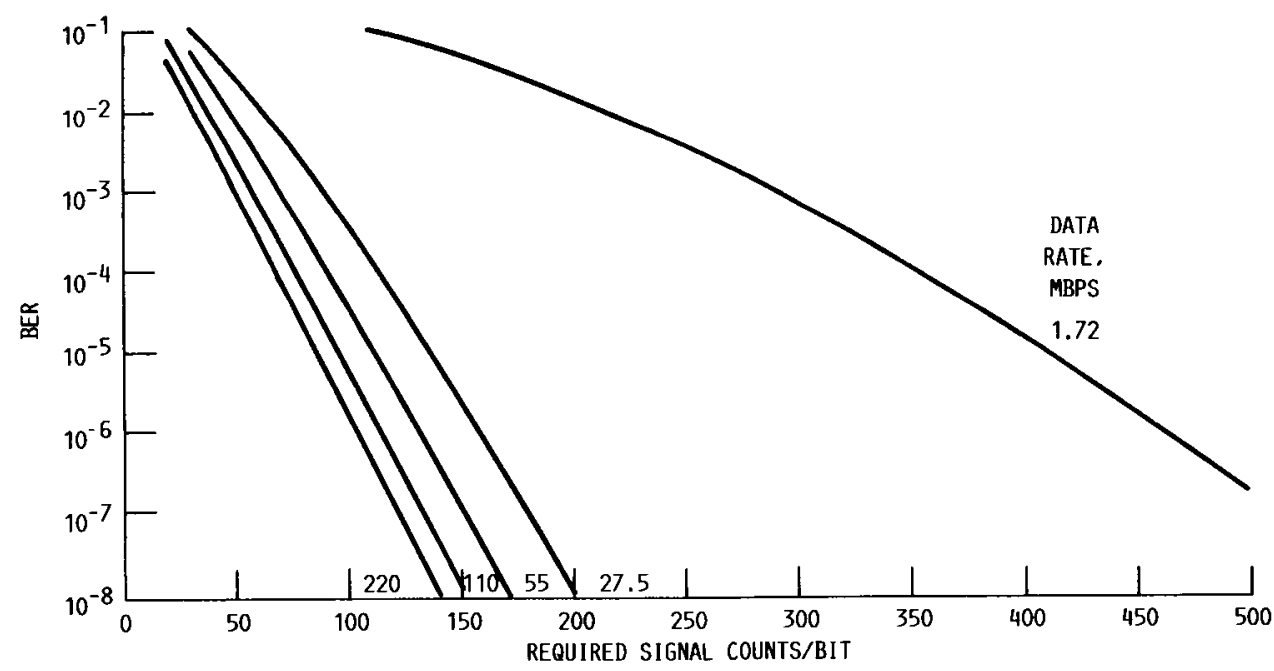

FIGURE 5. - BPPM BER VERSUS REQUIRED SIGNAL COUNTS/BITS, NO BACKGROUND RADIATION SOURCES IN ACIS OR AIRCRAFT RECV FOV. TS $=400 \mathrm{~K} ; \mathrm{RL}=2000$ OHMS: EXTINCTION -5 PERCENT; $\mathrm{G}=150$;

$F=3.5 ; \quad I S=10 \mathrm{NA} ; \mathrm{IB}=0.1 \mathrm{NA} ; \mathrm{QE}=0.70 ; \mathrm{NB}=0$ COUNTS $/ \mathrm{SEC}$. 


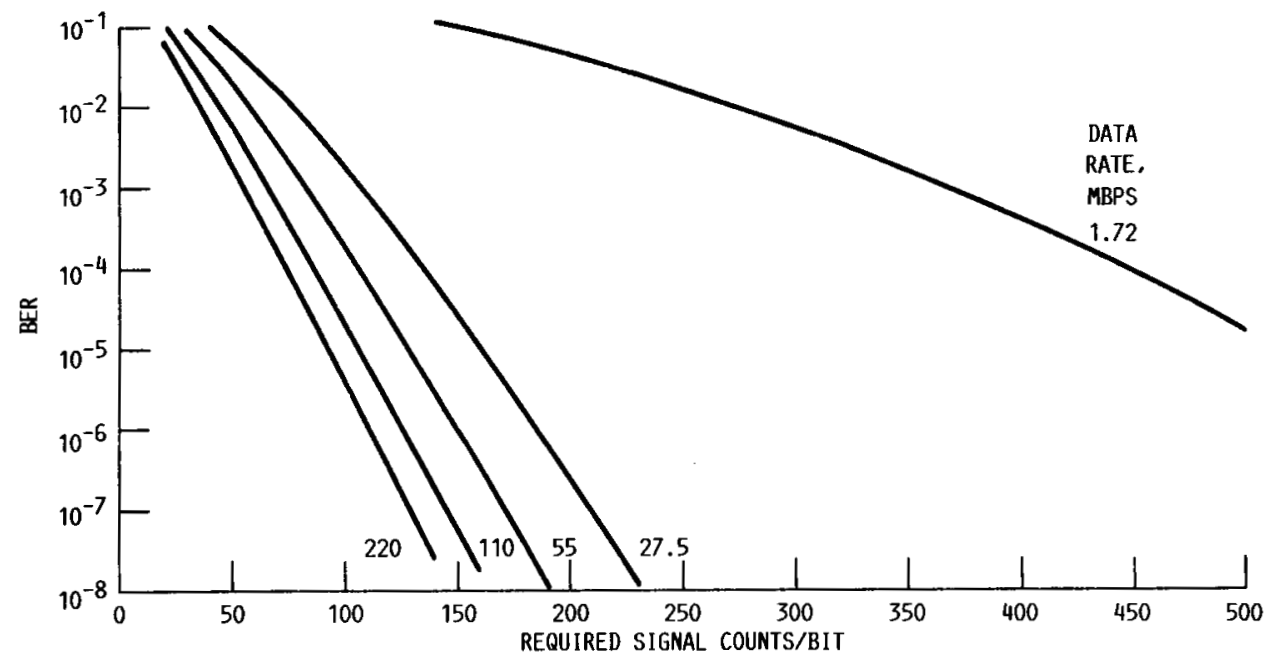

FIGURE 6. - ACTS BPPM BER VERSUS REQUIRED SIGNAL COUNTS/BIT. SUNLIT EARTH IN ACTS RECV FOV. $\mathrm{TS}=400 \mathrm{~K} ; \mathrm{RL}=2000$ OHMS $;$ EXTINCTION -5 PERCENT; $\mathrm{G}=150 ; \mathrm{F}=3.5 ; \mathrm{IS}=10 \mathrm{NA} ; \mathrm{IB}=0.1$ $\mathrm{NA}: Q E=0.07 ; \mathrm{NB}=2.2 \times 10^{9}$ COUNTS $/ \mathrm{sEC}$.

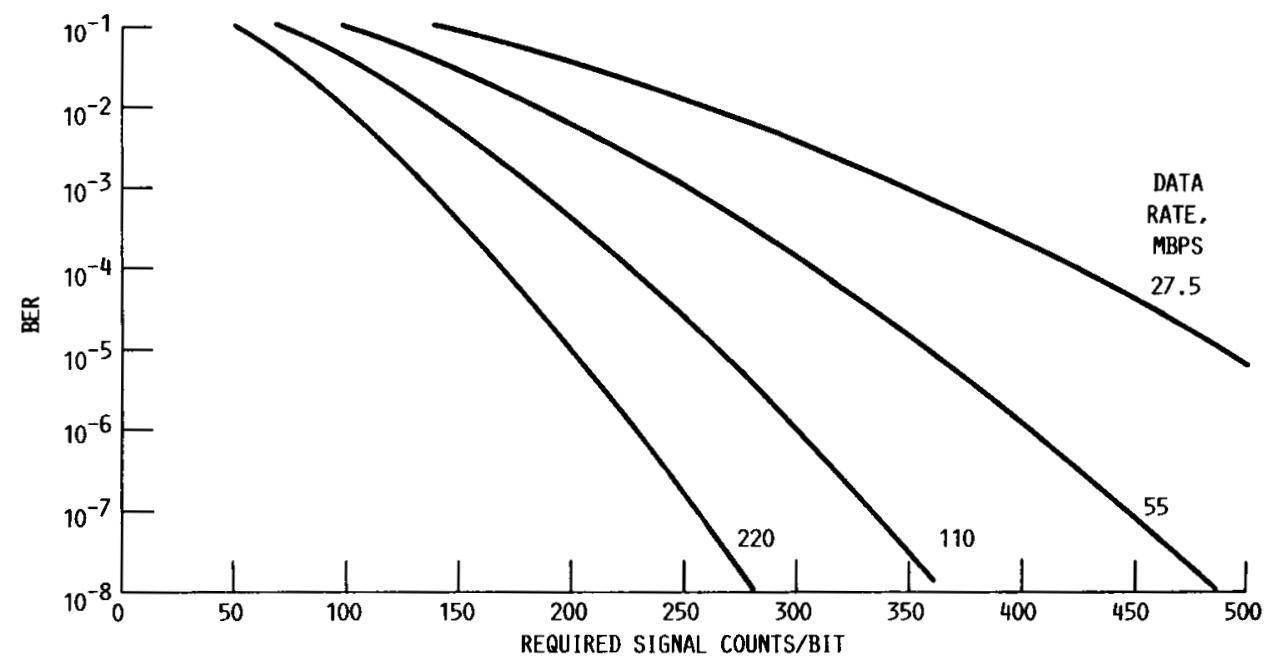

FIGURE 7. - AIRCRAFT BPPM BER VERSUS REQUIRED SIGNAL COUNTS/BIT, SUNLIT SKY IN ACTS RECV FOV, $T S=400 \mathrm{~K}: \mathrm{RL}=2000$ OHMS: EXTINCTION -5 PERCENT: $\mathrm{G}=150 ; \mathrm{F}=3.5 ; \mathrm{IS}=10 \mathrm{NA}$ : $\mathrm{IB}=0.1 \mathrm{NA}: \mathrm{QE}=0.70: \mathrm{NB}=7.6 \times 10^{10} \mathrm{COUNIS} / \mathrm{SEC}$. 


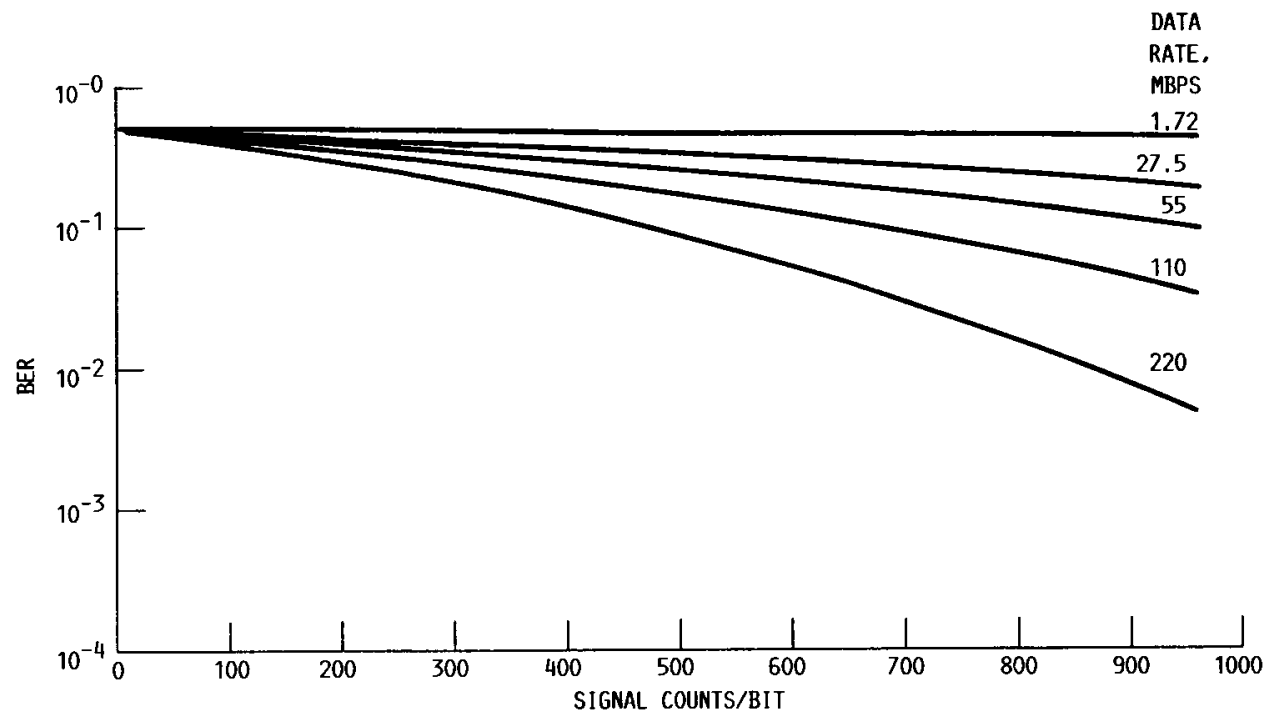

FIGURE 8 - AIRCRAFT BPPM BER VERSUS REQUIRED SIGNAL COUNTS/BITS. SUN IN AIRCRAFT RECV FOV. $\mathrm{TS}=400 \mathrm{~K} ; \mathrm{RL}=2000$ OHMS; EXTINCTION -5 PERCENT: $\mathrm{G}=150 ; \mathrm{F}=3.5 ; 1 \mathrm{~S}=10 \mathrm{NA}: \mathrm{IB}=0.1 \mathrm{NA}$; $\mathrm{QE}=0.70: \mathrm{NB}=7.6 \times 10^{12}$ COUNTS $/ \mathrm{SEC}$.

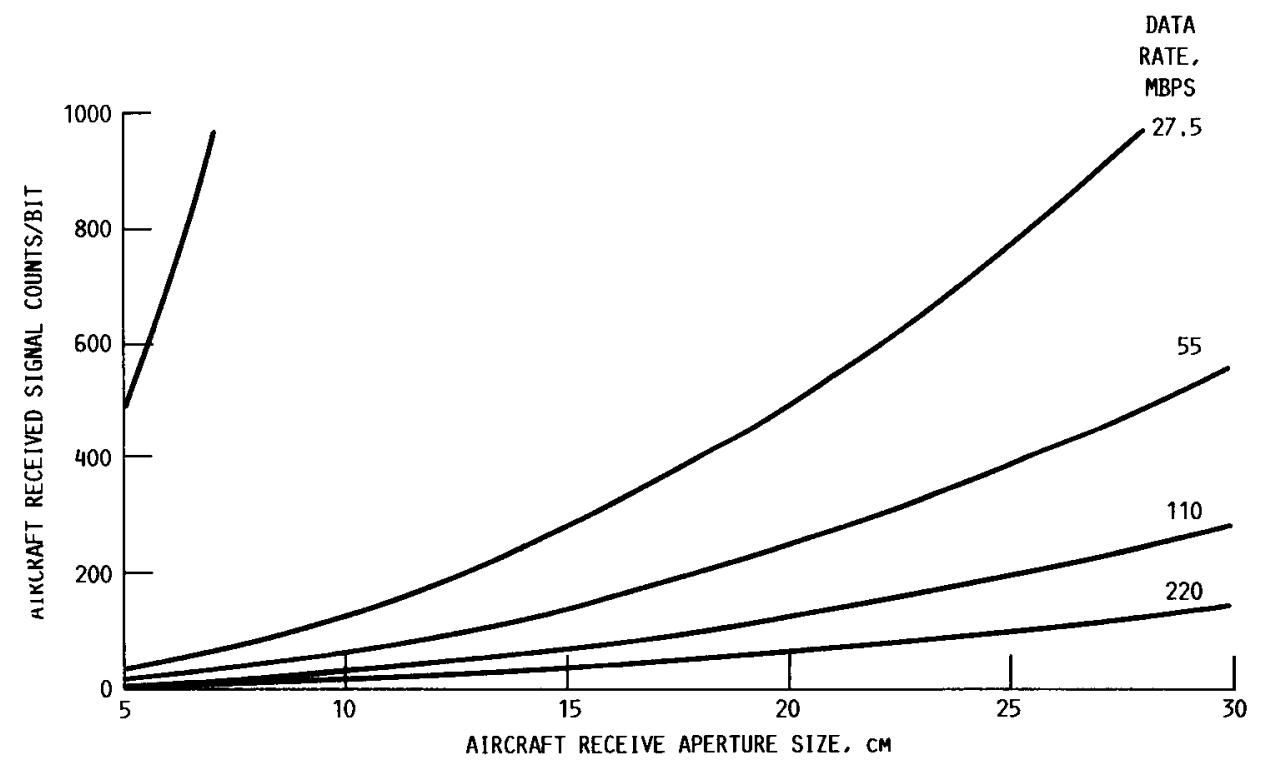

FIGURE 9. - RECV SIGNAL COUNTS/BIT VERSUS AIRCRAFT APERTURE DIAMETER. ACTS-TO-AIRCRAFT COMMUNICATION. PT $=30 \mathrm{MW}$ : XMIT EFF. $=40$ PERCENT; DT $=20 \mathrm{cM}$; POINTING LOSS $=1.02 \mathrm{~dB}$; ATMO LOSS $=0.8 \mathrm{~dB}$; RANGE $=38070 \mathrm{kM} ;$ RECV EFF. $=62$ PERCENT; OE $=70$ PERCENT. 


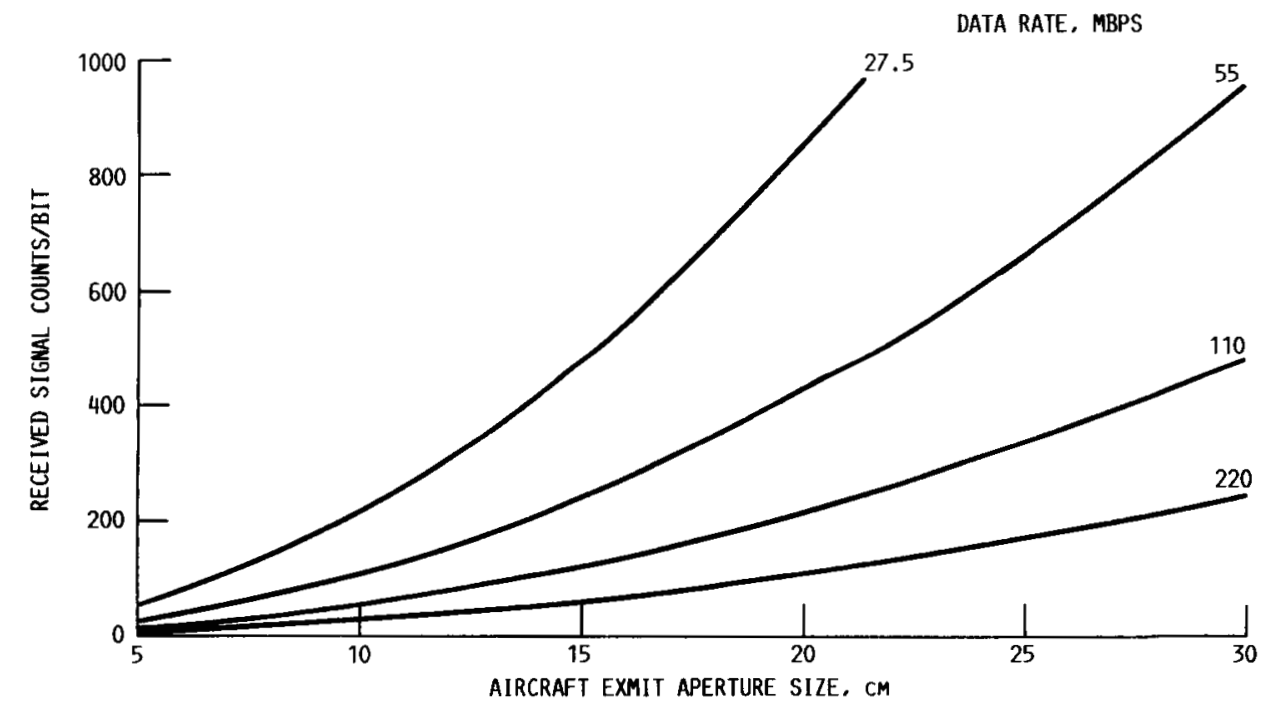

FIGURE 10. - RECV SIGNAL COUNTS/BIT VERSUS AIRCRAFT APERTURE DIAMETER, DATA RATES: 27.5. 55, 110 AND 220 MBPS. AIRCRAFT-TO-ACTS COMMUNICATION. PT $=50 \mathrm{MW}:$ XMIT EFF. $=40$ PERCENT DR $=20 \mathrm{cM} ;$ POINTING LOSS $=-1.02 \mathrm{~dB}:$ ATMO LOSS $=-0.8 \mathrm{~dB} ;$ RANGE $=38070 \mathrm{kM} ;$ RECV EFF. $=$ 62 PERCENT; $Q E=70$ PERCENT. 


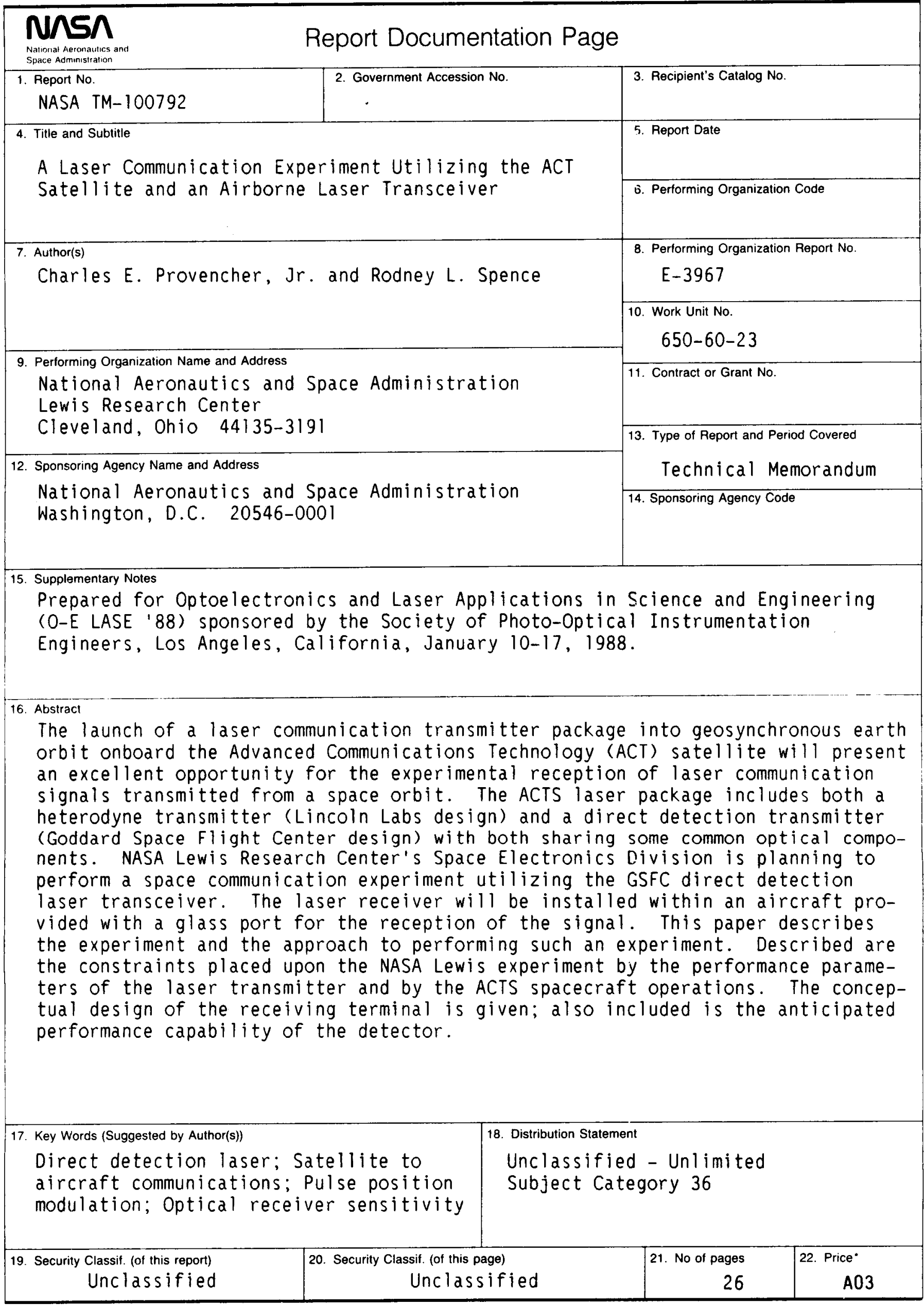

